Article

\title{
Missing Areas in the Bureaucratic Reputation Framework
}

\author{
Moshe Maor \\ Department of Political Science, The Hebrew University of Jerusalem, Jerusalem 91905, Israel; \\ E-Mail: moshe.maor@mail.huji.ac.il
}

Submitted: 28 January 2016 | Accepted: 29 March 2016 | Published: 23 June 2016

\begin{abstract}
Drawing on insights from social networks, social cognition and the study of emotions, this conceptual article offers a set of ideas and a series of predictions on how systematic variation in two sets of relationships may bear on agency behavior. The first is the agency-audience relationship which revolves around how and what multiple audiences think about public agencies, how these thoughts impact upon agency behavior, how information regarding this behavior is transformed within multiple audiences and how it influences audience memory and behavior regarding that agency. The second is the relationship between the reputation of an agency head and the reputation of that agency. The article identifies six broad areas that offer the most promising possibilities for future research on bureaucratic reputation, calling on researchers to incorporate insights from the aforementioned literatures, to dimensionalize these sets of relationships and to assess the generalizability of reputation's effects.
\end{abstract}

\section{Keywords}

agency head; audiences; bureaucratic reputation; emotion; social cognition; social networks

\section{Issue}

This article is part of the issue "New Approaches to Political Leadership", edited by Mark Bennister (Canterbury Christ Church University, UK).

(C) 2016 by the author; licensee Cogitatio (Lisbon, Portugal). This article is licensed under a Creative Commons Attribution 4.0 International License (CC BY).

\section{Introduction}

During the last decade or so, the concept of bureaucratic reputation and the derived process of reputation management in the public sector have been entering from off stage into the field of public administration (e.g., Wæraas \& Byrkjeflot, 2012; Wæraas \& Maor, 2015). On the cusp of the new millennium, scholars were exposed to the basic theoretical foundations for the study of bureaucratic reputation and autonomy in the shape of a seminal contribution by Dan Carpenter (2001). A decade later, another seminal contribution followed (Carpenter, 2010a). The bureaucratic reputation framework that has emerged is comprised of four elements: the specific view of reputation which enables an agency to claim a unique contribution to the public good; the multifaceted nature of reputation; the existence of multiple expectations by multiple audiences, and the context of today's knowledge society and blame culture which fosters conditions that intensify agency concerns with reputational risk (Maor, 2015). Agency is used here in its broad sense, that is, government authority, rather than in the narrow sense, that is, "modern" agency (Bach, Fleischer, \& Hustedt, 2010, p. 13).

Studies informed by this framework have revealed a large set of processes and phenomena. Recent findings have related to the consequences of reputational concerns for the way agencies approve some drugs more quickly than others (Carpenter, 2002) and allocate resources across tasks (Gilad, 2012). Additional research has dealt with endogenous construction of jurisdictions (Maor, 2010) and the observability of regulatory decisions and errors (Maor, 2011). Researchers have also examined the duration of enforcement decisions (Maor \& Sulitzeanu-Kenan, 2013), as well as the changes in an agency's outputs and the mix between its outputs and other activities (Maor \& 
Sulitzeanu-Kenan, 2016). Still other studies have demonstrated the extent and the ways regulatory agencies manage their reputations through the strategic use of communications (Gilad, Maor, \& Ben-Nun Bloom, 2015; Maor, Gilad, \& Ben-Nun Bloom, 2013). Carpenter (2001, 2010a) has offered some generalized answers to issues regarding reputation and power, and has summed up the contribution of this scholarly literature: "The lesson of this scholarship is that, when trying to account for a regulator's behavior, look at the audience, and look at the threats" (Carpenter, 2010b, p. 832 ; italics in original).

Given these insightful findings, it is rather surprising that so little attention has been devoted to the social processes by which collective perceptions regarding a public agency emerge. At the end of the day, social approval or disapproval of an agency is based on collective perceptions. But precisely how do such perceptions emerge? What mechanisms are at play throughout this process amongst multiple audiences who may have dramatically different values and expectations? What forms of communication are embedded within different segments of society that facilitate or inhibit the transmission of reputation-relevant information? Furthermore, under some conditions, traits and/or behaviors of individuals within an agencyespecially the agency head-may be linked together in the minds of members of the political elites and the general public. What people know about an agency may parallel what they know of the agency head. Besides, if the agency head is famous by virtue of his past achievements, he or she may be deemed worthy of attention. So what is the relationship between an agency head's reputation and agency reputation in a mediasaturated environment? The need to deepen our understanding of Carpenter's insights is therefore of utmost importance.

Drawing on robust findings from social networks, social cognition and the study of emotion, this article offers a set of ideas and a series of predictions on how systematic variation in two sets of relationships may bear on agency choices. The first is the agencyaudience relationship which revolves around how and what individuals, groups and society as a whole think about public agencies, how people's thoughts and concerns impact upon agency behavior, and how information regarding this behavior is transformed within multiple agencies, and influences audience memory and behavior regarding that agency. In other words, how does agency response to reputational threats reverberate amongst different audiences and feed back to the agency's perception of reputational threats and opportunities? The second is the relationship between agency head reputation and the reputation of that agency. For example, what impact does a newly appointed agency head with a good or bad reputation have on the agency's behavior and how long is this maintained? Understanding these two sets of interactions is fundamental to grasping the process by which bureaucratic reputation emerges, assessing the importance of reputation and its role, and understanding how to manage it effectively. This paper is therefore meant to be expositional and exploratory. The aim is not to provide an overall analytical framework but rather to sketch out the pieces of two missing parts in the bureaucratic reputation framework, and to conjecture as to how bureaucratic scholars should empirically confront them. Furthermore, the aim is not to elaborate the state of the art of bureaucratic reputation theory-a task recently undertaken elsewhere (Wæraas \& Maor, 2015), but rather to develop a research agenda which is rooted in a political science approach.

The article identifies six broad areas that offer the most promising possibilities for future research on bureaucratic reputation: (1) the manipulation of emotions by an agency in order to increase the audience's attention to some reputation-relevant information; (2) the variation in audience information processing and behavior as derived from the relative importance they attach to an agency; (3) the variation in audience information processing and behavior as derived from cultural attributes; (4) the variation in communication strategies undertaken by agency heads who enjoy a good reputation compared to those who enjoy a bad or indistinct reputation; (5) the variation in the alignment of agency heads, who enjoy different levels of reputation, with the agency's main audiences and with the agency management, and (6) the variation in the agency's strategies with potential negative consequences which are executed by agency heads who enjoy a good reputation as compared to those who enjoy a bad or indistinct reputation. The article calls upon researchers to incorporate insights from the literatures of social networks, social cognition and emotion, to dimensionalize the aforementioned sets of relationships and to assess the generalizability of the effects of reputation.

The article proceeds as follows: the second section explores the ideational and definitional grounds, the third elaborates on the major premises of bureaucratic reputation as an audience-based approach; the fourth focuses on the role of the media in the interplay between agencies and audiences, the fifth elaborates on the main premises of agency head reputation and its interaction with agency reputation, the sixth discusses the link between agency head reputation and agency autonomy - a link which is at the heart of the political science approach to bureaucratic reputation, and the seventh briefly elaborates on the measurement of organizational reputation as well as the reputation of the agency head. The final section concludes. Before delving into the substance of this article, the next section considers early research in bureaucratic reputation and the setting up of the definitional ground. 


\section{The Ideational and Definitional Grounds}

Scholars of politics have long been aware of the need to look at reputational concerns at the individual and organizational levels. According to Goffman (1959), for example, many aspects of politics are not only about overseeing or giving account but also about advancing one's standing in the eyes of one's audience and about being seen as a reputable actor. This is why "[...] the formative years of a policy-making agency are of crucial importance in determining its behavior" (Wilson, 1989, p. 68). During the formative years, "[a]mong the critical decisions facing leadership, closely related to the definition of mission, is the selection of a clientele, market, target, allies, or other segment of the environment to which operations will be oriented" (Selznick, 1957, p. 104). Recognizing the importance of this selection process requires a nuanced understanding of the role of culture in the environment within which agency operates. This is because "[i]n order for a reputation to have an effect, both sides involved in a transaction must ex ante have some idea of the meaning of appropriate or equitable fulfillment of the contract" (Kreps, 1990, p. 93; italics in original). The traditional view is that agency culture is insulated from external political and social forces. In contrast, the bureaucratic reputation perspective is premised on the idea that bureaucratic culture (read, "internal culture") influences key parameters in an agency's operation and language through agency interaction with institutional actors, such as political executives, legislators, advocacy groups and political parties-all are operating within a particular cultural context (read, "external culture") (Carpenter, 2001, p. 376, fn. 22). This inseparability of "internal" and "external" cultures (Kreps, 1990) is equally relevant in the relationships between politicians and bureaucrats. Moe (1984), for example, lays out in simple terms the role of bureaucrats' reputation as an important mechanism that facilitates the monitoring job of politicians over the bureaucracy. According to Moe, "[o]ne [mechanism] is the reputation of bureaucrats. Over time, politicians are able to observe bureaucratic behavior and, for many of the more important actors, arrive at tacit agreement as to their honesty, competence, ideology, innovativeness, and other qualities of relevance" (1984, p. 767).

Despite how insightful and thought-provoking the aforementioned observations were, they did not trigger much research on bureaucratic reputation during the 1980 s and 1990s, although some political scientists did make contributions to this subfield (Heimann, 1997; Quirk, 1980; Rourke, 1984; Wilson, 1989; Whitford, 2002). However, that has changed since Carpenter (2001) first noticed that agencies attempt to cultivate reputation that will enable them to gain autonomy, and theorized about it. According to Carpenter (2010, p. 33), "[r]eputations are composed of symbolic beliefs about an organization-its capacities, intentions, history, mission-and these images are embedded in a network of multiple audiences." This definition, over which there is no disagreement among scholars (Maor, 2015, p. 19), centers on the evaluation of the organization's unique character and activities by multiple audiences. Reputation uniqueness, according to Carpenter (2001, p. 5), refers to the demonstration by agencies that they can create solutions (e.g., expertise, efficiency) and provide services (e.g., moral protection) that no other agency in the polity offers. This idea resembles the notion of "distinctive competence" labeled by Philip Selznick (1957) who claimed that it is the role of organization leaders to advance and protect such competencies and the resources underlying them. This implies that bureaucratic reputation relies on the external audiences' perceptions of the quality of agency outcomes that these audiences really care about, and the effectiveness of its actions, which distinguish the agency from others in the polity.

\section{Bureaucratic Reputation as an Audience-Based Approach}

In this section, we offer relevant observations regarding agency-audience relationships when social network and social cognition perspectives are taken into account. A convenient starting point is the premise that audiences observe public agencies. When they do so, they bring into play a variety of factors including prior knowledge, goals, mental frames, heuristics, distraction, motivation, emotion, and others. Ultimately, issues arise concerning what the audience will remember about the agency, what information regarding the agency will be suppressed (e.g., Najmi, 2013), and how information that audiences rely upon in shaping their attitudes contributes to their judgment regarding the agency. But audience descriptions and perceptions of bureaucratic agencies are remarkably diverse and may change over time. This diversity arises because audience perceptions are not about physically objective reality. What they "see" in agencies is largely inferred, assumed and/or felt, and may vary across time, culture, and subculture (Carpenter \& Krause, 2012).

Taking into account the "social" and the "psychological" requires delving into the audiences' histories, key personalities, relationships, motivations, goals, intentions, and plans. Together with various aspects of the audience's social environment, these factors converge to shape the communication and interaction between audience members, and the processes by which they come to understand social reality (e.g., attribution and attitude formation). Audiences strive to make sense of agency actions by wondering about their causes, and vice-versa. They may do this directly, or by relying on institutional intermediaries, such as the media and various specialized organizations, or other agencies or audiences. 
Of greatest relevance is the fact that the interpretation of information is context dependent because being socialized in a given context implies acquiring cultural, behavioral and other assumptions. These contextual factors prioritize different motivations and preferences which lead to different ways of perceiving reality. For example, Western cultures revolve around individualistic values, emphasizing the needs of the self over others (e.g., Greenwald, 1980). This, in turn, may produce a focused attentional strategy (Balcetis \& Cole, 2013). Asian cultures, on the other hand, are considered collectivist, given their emphasis on group happiness and the happiness of significant others over the needs of the self (Balcetis \& Cole, 2013). Collectivist cultures may cause attention to be dispersed among different objects (e.g., Duffy \& Kitayama, 2010). Different ways of perceiving reality imply different reputational threats and opportunities derived from different audiences. Cultural factors may therefore contribute toward an explanation of the ways agencies prioritize different audiences over time and the ways audiences prioritize different agencies over time.

The aforementioned processes also result in information communicated to the agency whose outcomes affect whether those involved will interact again, under what circumstances and for what purposes; whether they will influence or affect each other in other ways, even in absentia; or whether the whole interaction will be remembered or will lead to enduring changes in their attitudes, intentions and expectations. Audiences may expect different things from different agencies over time, and so the same agency behavior may produce different reputational consequences for different agencies. Audiences may also have conflicting expectations from some agencies, and complementary expectations from others. And some audiences' expectations may be more prominent, and more consequential than others. In addition, information about public agencies may be processed differently than information about individuals and groups. The key point here is that agencies may have specific relationships with particular audiences in particular time periods. Another point is that many aspects of the interrelationships between agencies and audiences might be better understood in terms of what we know about social networks, social cognition and affective experiences (e.g., moods, emotions)-both as constraints and as targets for instrumental manipulation - which are fairly distant from bureaucratic politics.

How do theories of emotion and affect bear on theories of bureaucratic reputation? Emotion generally refers to particular feelings (e.g., sadness, anger) that are "intense, short-lived, and usually have a definite cause and clear cognitive content" (Forgas, 1992, p. 230). Affect, according to Finucane, Peters, \& Slovic (2003, p. 328), refers to ''goodness' or 'badness' (1) experienced as a feeling state [...] (2) demarcating a positive or negative quality of a specific stimulus [...]". Emotion and affect influence behavior in two distinct ways. First, people anticipate and factor in their likely feelings about the potential consequences of different modes of agency actions. Second, people may be influenced by immediate emotions experienced at the moment of choice (e.g., Rick \& Loewenstein, 2010) among bureaucratic agencies and at the moment of choice among the public goods they produce.

Two interrelated streams of research-one concerns affect (i.e., good/bad feelings) which is represented by the affect heuristic, and another concerns affect-as-information-provide ample evidence of the impact affect and emotion have on subjective probabilities, value, and risk-benefit balance (for a review, see Finucane, 2013). The affect heuristic refers to people's tendency to base their judgment (e.g., of a public product, agency, or policy) on what they think and feel about it (e.g., Finucane, Alhakami, Slovic, \& Johnson, 2000 , p. 5). "If they feel good about [it], they tend to judge risks as low and benefits as high; if they feel bad about it, they may judge the opposite [...]" (Peters, 2011 , p. 90). The affect-as-information literature "asserts that affective reactions serve as information about what one likes or dislikes" (Clore \& Palmer, 2009 , p. 22). According to this line of thought, Zajonc (1980, 1984), Bargh (1984) and LeDoux (1996) have demonstrated that affective reactions to stimuli are faster than cognitive evaluation, and therefore provide a crude assessment of the behavioral options people face. Recently, Lodge and Taber (2013) found that "[...] all thinking is suffused with feeling, and these feelings arise automatically within a few milliseconds [...] of exposure to a sociopolitical object or event" (p. 19). The affect heuristic combined with Lodge and Taber's (2013) findings imply that agencies operating in relatively high emotional domains, such as those concerning life and death (e.g., the U.S. Food and Drug Administration, the European Medicines Agency and the European Food Safety Authority) may face a relatively high level of emotion-based audience reactions compared to agencies operating within relatively neutral domains (e.g., Groenleer, 2014). In other words, an agency has to factor in the possibility that audiences with different emotional attributes and at different emotional states may respond differently to different types of news concerning the agency.

Further, an agency may attempt to influence which emotions its audiences have, when they have them, and how they experience and express these emotions (Maor \& Gross, 2015). At the same time, an agency may be exposed to attempts undertaken by emotional entrepreneurs (Maor \& Gross, 2015) to influence audiences' emotions towards the agency. In addition, because agency tasks are multi-dimensional, agencies operating in emotional domains can be criticized for technical tasks, which are not emotionally laden, while 
agencies working on more neutral domains can be criticized on moral aspects of their reputation, which are more emotionally laden. In essence, this calls for studies that take into account the emotions attached to the domain in which the agency operates, contingent on the specific dimension (i.e., performative, technical, procedural and moral) that is challenged with related task characteristics and on the emotional entrepreneurs that operate in the policy domain.

But how do audiences prioritize different expectations over time? Specifically, how independent are the dimensions by which audiences evaluate agencies? Do these dimensions reflect the real, underlying behavior of public agencies, or merely audiences' perceptions about agency characteristics? And how independent are the dimensions by which agencies evaluate audiences? Carpenter (2010) has directed attention towards key dimensions, be they performative, moral, procedural, and technical traits of the organization. An agency does not have a strong reputation per se, but rather a strong reputation for the protection of public safety, public health, public morality and so on. Carpenter's four faces of an agency's reputation highlight the dimensions over which the relative standing of the organization is assessed vis-à-vis other agencies. Carpenter's statement also implies the existence of multiple reputations-and therefore, multiple expectations by external audiences regarding each of these dimensions. Each external audience selects the dimension/s of reputation which will receive priority in its assessment of the organization. But do audience perceptions vary along Carpenter's (2001) four dimensions of competence? When audiences undertake comparative judgments of agencies, do these dimensions have a compensatory relationship so that, for example, learning that an agency is high on the performative trait lowers estimates of morality (e.g., in the case of an agency in charge of deporting illegal immigrants)? In other words, do some audiences tend to differentiate dimensions of agency reputation in a comparative context in a compensatory direction? These questions should be central to our subfield but are not.

\section{Agencies, Audiences, and the Role of the Media}

As an audience-based approach, the bureaucratic reputation framework seriously takes media coverage on board. Recent studies have already demonstrated the extent and the ways regulatory agencies manage their reputations through the strategic use of communications (e.g., Gilad, Maor, \& Ben-Nun Bloom, 2015; Maor, Gilad, \& Ben-Nun Bloom, 2013). Agencies also build reputation by shadowing practices and policies pursued by agencies that possess good reputations (Maor, 2007, 2011); by affiliating with established players and by appointing top management teams who enjoy good reputations (Petkova, 2012).
When an agency is first encountered, an audience starts by categorizing the agency based on salient features of characteristics and behaviors. When an audience is first encountered, agencies start by doing the same thing. Although media coverage can serve to bias the perceptions of both agencies and audiences, they can also attune perceivers to each other's actions, evaluations and behavior. Thus, media coverage can bias perceivers and make them more sensitive to certain signals, and moderate the accuracy with which agency behavior is recognized. Specific agency behavior can also attune audiences to functionally important actions and other signals. These signals can mobilize perceivers' cognitive and perceptional resources in preparation for action. Thus, certain signals may be capable of attuning perceivers to relevant agency behavior.

Agency characteristics and behavior may place it in certain categories in audiences' perception. These effects may be ramified throughout subsequent stages of information processes. Furthermore, what an audience perceives may be due, in part, to what it expects to see-its expectation and belief regarding the agency. Although these perceptions and thoughts are influenced by media coverage, they are also motivated phenomena-audiences may work harder to extract (accurate) information regarding certain agencies relative to others. Audiences may also be better at encoding and remembering information regarding agencies whose operations are important to them, relative to others. For example, decisions by the U.S. Environment Protection Agency may be more important to environmental policy interest groups than to education policy interest groups. This tendency of audiences to readily think about public agencies which are important to them is not a point of debate. The question is not whether agency characteristics and behaviors are important in reputation formation but rather when they are more likely to be influential in the interpretation of structurally and situationally invariant information.

The discussion on agency audiences leads to the following propositions:

(i) When faced with negative media coverage, an agency will tend to manipulate emotions in order to ensure that its audiences selectively attend to some types of information regarding the agency while ignoring others.

(ii) An agency's perception of each of its audiences will determine what information is generated for consumption by each audience, how that information is generated, how the feedback is evaluated, and what inferences are drawn from it.

(iii) Audiences will more quickly process differences between past and present agency behavior for agencies whose operations are important to them. 
(iv) Audiences will more quickly infer agency characteristics from the behavior of agencies whose operations are important to them.

(v) Audiences may be better at encoding and remembering information regarding agencies whose operations are important to them.

\section{Agency Head's Reputation}

Although many bureaucracy scholars emphasize the importance of agency heads (Aberbach \& Rockman, 2000; Adolph, 2013; Busuioc \& Groenleer, 2012; Carpenter \& Krause, 2012; Kaufman, 1981; Seidman \& Gilmour, 1998; Wilson, 1989), scholars of organizational reputation tend to ignore the reputation of the single leader at the top of an agency's hierarchy in their explanations of agency behavior. Agency head here refers to an individual who is statutorily authorized to make legally binding decisions on behalf of an agency. The agency head's reputation can be conceptualized along Carpenter's (2001) coordinates as a set of beliefs about an agency head's individual capacities, values and intentions that are embedded in audience networks.

The tendency to ignore the reputation of agency heads may lie in the similarity between the factors that influence agency head's reputation and those that influence organizational reputation, or in the methodological obstacles that hamper the ability of scholars to differentiate between these two constructs in normal practice. This neglect may be justified as long as one assumes that agency-head reputation moves in tandem with organizational reputation, and that agency heads' incentives are fully aligned with those of their organizations. This assumption is sensible insofar as audiences' assessments of agency heads affect organizational reputation and vice versa. However, there are a number of key differences between these two constructs, namely, the shorter horizon over which the agency head can build his or her reputation compared to an agency that has been doing it for decades; the relative instability of the agency head reputation when new information is revealed relative to organizational reputation which has been developed over multiple decades, and the portability of the agency head's distinct reputation (Graffin, Pfarrer, \& Hill, 2012). Furthermore, there are certain times at which these two constructs may move in separate directions-for example, when a change in agency head leads to agency reputation and agency head reputation to converge around the average level of reputation. These differences raise a question which to the best of my knowledge has never been examined: What impact does a newly appointed agency head with a good/bad reputation have on agency behavior and how long is it maintained?

\section{Bureaucratic Autonomy and Agency Head's Reputation}

Bureaucratic reputation has been considered a key factor in determining agency autonomy. Autonomy prevails, according to Carpenter (2001, p. 4), when agencies can establish a reputation and persuade political executives to defer to agency wishes. "Under these conditions, politicians grant agency officials free rein in program building" (Carpenter 2001, p. 4). Given that the same factors that contribute to agency autonomy may differentiate among agency heads, it is rather surprising that agency autonomy has become a wellcharted territory, but less so, the variance amongst agency heads. Take, for example, professionalism (Weber, 1946; Wilson, 1989). According to Wilson, "[i]n a bureaucracy, professionals are those employed who receive some significant portion of their incentives from organized groups of fellow practitioners located outside the agency" (1989, p. 60). However, Wilson does not consider the possibility that there are professionals in administrative agencies who enjoy worldwide esteem (e.g., FDA Medical Officer Frances Kelsey who reviewed the thalidomide case), others that enjoy good reputation in the geographical region or in the relevant territory, and others who enjoy bad or indistinct reputation. Other factors contributing to agency autonomy and thereby to the differentiation among agency heads are the cultivation of external audiences (Carpenter, 2001, 2010) and the management of audiences' conflicting views and assessment criteria in light of the agency's understanding of its distinct multidimensional reputation (Gilad, Maor, \& Ben-Nun Bloom, 2015; Maor, Gilad, \& Ben-Nun Bloom, 2013); the pursuit by agencies of "strategic neutrality", i.e., when agencies act politically in a way that does not unite opponents (Huber, 2007); the presence of multiple competing principals (Hammond \& Knott, 1996), and the inattention by elected officials who operate alongside well-informed bureaucrats (Calvert, McCubbins, \& Weingast, 1989).

Agency heads may also vary in their ability to strike political bargains at the national or federal levels and adhere to these bargains by imposing systematic and uniform local enforcement policies. They may also vary in their ability to pit one principal against another (Kiewiet \& McCubbins, 1991), manipulate principalagent relationships (Riker, 1986) and manage informal compliance and resistance mechanisms in bureaucratic politics (Carpenter \& Krause, 2015). Some agency heads may be well-informed relative to other agency heads and possess the necessary skills to transfer information into knowledge (i.e., "connect the dots"). Some agency heads may be loyal to the president who picked them (Krause \& O'Connell, 2015), and some may fit the political environment of bureaucracy insofar their ideology is concerned (Bertelli \& Grose, 2009, 2011; Clinton, Bartelli, Grose, Lewis, \& Nixon, 2012; 
Nixon, 2004). Agency heads may also vary in their career concerns (Adolph, 2013; Alesina \& Tabellini, 2007; Dewatripont, Jewitt, \& Tirole, 1999) and in their level of care about their organizational identity, especially in terms of their preferences for cooperation or for team spirit when they serve an assigned role and function within the organization (Akerlof \& Kranton, 2005; March \& Simon, 1992).

The aforementioned variance in agency heads' ability, ideology and care of organizational identity may lead to variability in their reputations as well as in their concerns about the risks and opportunities associated with their future reputation (and compensation). In addition, different audiences may be differently affected by the aforementioned traits. This, in turn, calls for a more in-depth analysis of the mediating role of audiences in shaping agency heads' reputation, and thereby, the variability in agency heads' reputations. Given that bureaucratic agencies have, to a greater extent, become mediatized, the same goes for the head of the communications department who handles the actual day-to-day processes of reputation management.

In the modern-world media environment, reputational concerns of agency heads may extend beyond the internal games agency heads play to manipulate principals' inferences regarding their ability, ideology and so on. At the outset, the social construction of leadership images involves, among others, the belief that individuals determine the fate of organizations (Chen \& Meindl, 1991, p. 524). When this belief bears on the popular press and its readership, the risk management agenda of an agency head expands. Further, in the modern information environment, all major policy decisions made by agency heads are observed, and so are all relevant agency outcomes. In addition, national and international league tables, which provide quality metrics for agency and agency head reputation, are "[...] perceived and articulated as a source of reputational risk" (Power, Scheytt, Soin, \& Sahlin, 2009, p. 302). However, the media still seeks interpretations of these decisions and outcomes. Negative commentary by informed or expert third parties, such as the business press (e.g., Zuckerman, 1999), may tilt the probabilities towards opinions that are reputationally less favorable for agency heads. Consequently, some agency heads may enter the fray by adopting various presentational strategies (Hood, 2011) in an attempt to explain their objectives, methods and decisions. Others will do so on a smaller scale, and some may even consider keeping silent (Maor, forthcoming). Whether to intervene in the media environment, and if so, how "loud" should one do it, may be directly related to an agency head's reputation. This, in turn, is most likely to be manifested when an agency encounters shocks in the form of agency head succession and following an unexpected positive or negative event (Graffin et al., 2012). In both cases agency reputation and agency head reputation are likely to be distinct. In the former case, this is due to the early stages in the agency head's tenure, in the second, the relatively high visibility of agency policy and the agency head's presentation of this policy. Questions related to these interrelationships and the derived reputational mechanisms at work should come to the fore in the area of bureaucratic reputation.

The discussion of an agency head's reputation raises the following propositions:

(i) Agency heads with a bad or indistinct reputation might fight hard to build a positive reputation, and thus respond vigorously and "loudly" to any hint of criticism in all of the above cases. By contrast, an agency head who enjoys a good reputation is more likely to talk less when facing criticism. In addition, an agency head with a bad or indistinct reputation is expected to be more inclined to respond to public judgments, especially during his or her early tenure and shortly before the end of tenure.

(ii) Agency heads with a bad or indistinct reputation are more likely to be aligned with the agency's main audiences rather than with the agency management. By contrast, agency heads with a good reputation are more likely to be aligned with the agency management rather than the agency's main audiences.

(iii) Agency heads with a bad or indistinct reputation are more likely to be concerned with both the level and variability of their reputation when compared to agency heads who enjoy a good reputation.

(iv) Agency heads at the early stages of their career will be less likely to engage in activities which have potentially negative consequences when compared to agency heads who enjoy a good reputation.

(v) Agency heads who enjoy a good reputation will tend to increase transparency especially regarding their active, bolder policy activities when compared to agency heads with a bad or indistinct reputation.

(vi) When agency heads enjoy a good/bad reputation, the level of agency reputation will converge towards the level of the agency head's reputation.

\section{Measurement}

None of the current bureaucratic reputation scholars measure reputation per se, but rather reputational threats as manifested in the media. There is however a literature that compares citizen's perceptions of agency performance relative to their expectations and considers the impact of widely disseminated agency performance information on citizen perceptions (e.g., 
Jacobsen, Snyder, \& Saultz, 2014; Lavertu, 2015). There are also studies that consider the ideological reputation of U.S. agencies, applying measurement models to synthesize the perceived reputation of agencies among experts (e.g., Clinton \& Lewis, 2008). Organizational theory scholars have also wrestled with the measurement of reputation, with some applying an overall measure while others apply an attribute-specific measure (Dowling \& Gardberg, 2012). For example, Fombrun (2012) defines firm reputation as a collective assessment of a company's attractiveness to a specific group of stakeholders relative to a reference group with which the company competes for resources. This conception, therefore, implies an overall measure of "attractiveness". At the same time, reputation varies across audiences and attributes because it is directed toward specific stakeholders. As a result, firms can have multiple reputations (Greenwood, Parkish, \& Deephouse, 2005; Jensen \& Roy, 2008). Reputation additionally accounts for past behavior and/or performance (Jensen \& Roy, 2008; Washington \& Zajac, 2005). Because of these characteristics, Jensen, Kim and Kim (2012) make the case that a firm's reputation should be attribute-specific rather than an overall assessment. Scholars of bureaucratic reputation should note that much of the reputation literature in organizational studies is moving in this direction. At the same time, there are numerous indicators of a firm's reputation that are not available to scholars of bureaucratic reputation, such as share prices and the existence of long-term, global and local, consumer-based reputational rankings. Thus, there still remains a scope for gaining interesting insights regarding bureaucratic agencies by using the overall measure.

Regarding the measurability of agency head reputations, drawing on the methodological insights of studies of corporate reputation (Graffin et al., 2012; Milbourn, 2003), one may focus on five indicators which capture the variance in agency head reputation within a defined period, namely, agency head experienceoperationalized in terms of their last-post tenure; background-whether the agency head was hired from inside or outside the agency; performance in their last post-operationalized in financial and organizational terms; CEO awards, and media salience-a count of press articles that mention the agency head's name.

\section{Conclusions}

Reputation approach to bureaucratic organizations embraces a large set of processes and phenomena (e.g., Busuioc \& Lodge, 2015; Maor, 2015). However, it is challenged here as lacking in crucial components, namely, agency-audience interrelationships, and the relationships between agency head reputation and agency reputation. The prototypical scenarios arguably involve an agency which encounters a reputational threat and then reacts in order to protect its reputation. But missing is the perceiver of agency actions who encounters or learns about the agency's (and the agency head's) efforts to protect and enhance its reputation, the ways he/she refines an impression, and thereafter, the various thoughts and memories which subsequently shape his or her behavior regarding the agency (and the agency head). Missing also is the richness of the multiple transformation of the information communicated by the agency to a given audience. Further, the way agency response to reputational threats reverberates amongst different audiences $(6,2014)$ may impact on the relationship between agency head reputation and the reputation of that agency. This is because culture underlies an agency's reputation with its employees and clients, and "the violation of the culture will generate direct negative externalities insofar as it weakens the organization's overall reputation" (Kreps, 1990, p. 126). So far, the literature on bureaucratic reputation has not delved into these issues, but an interesting research agenda awaits those answering this article's call for action.

But why should scholars of bureaucratic politics bother to develop reputational theories beyond Carpenter? According to Maor (2015), Carpenter puts too much emphasis on the exogenous threats to agency reputation while underestimating their endogenous processing, given agencies' understanding of their distinct reputations. The agency-audience relationships as well as the relationships between agency head reputation and agency reputation may play a key role in the intra-agency process of interpreting and acting upon reputation information. This role is currently an uncharted territory. In addition, Carpenter too greatly emphasizes the institutional persistence of legislative and presidential decisions which lend stability to bureaucratic autonomy, thereby lending stability to good reputation. But institutional persistence cannot be guaranteed, as indicated, for example, by Lewis's (2002) finding that $62 \%$ of U.S. agencies created between 1946 and 1997 have been terminated and that political turnover is one of the primary causes of termination. Assuming that agencies recognize the possibility of termination following, for example, a significant operational failure, it is reasonable to expect that reputation information will be seriously looked at and acted upon. The agency-audience relationships as well as the relationships between agency head reputation and agency reputation may play a key role in this process.

\section{Acknowledgements}

This article is derived from two research projects supported by grants from the Fritz Thyssen Foundation ( $\mathrm{Az}$ 10.11.2.132) and the Israel Science Foundation (1002/ 11). I am grateful to Sharon Gilad, Pazit Ben-Nun Bloom and the anonymous reviewers for their excellent feed- 
back. All remaining errors are my own.

\section{Conflict of interests}

The author declares no conflict of interests.

\section{References}

6, P. (2014). "Reputation" theories of accountability: Have we got any yet? PowerPoint presentation, LSE Workshop "Accountability: New Perspectives", May.

Aberbach, J. D., \& Rockman, B. A. (2000). In the web of politics: Three decades of the US federal executive. Washington, DC: Brookings Institution.

Adolph, C. (2013). Bankers, bureaucrats, and central bank politics: The myth of neutrality. Cambridge, NY: Cambridge University Press.

Akerlof, G. A., \& Kranton, R. E. (2005). Identity and the economics of organizations. Journal of Economic Perspectives, 19(1), 9-32.

Alesina, A., \& Tabellini, G. (2007). Bureaucrats or politicians, part I: A single policy task. American Economic Review, 97(1), 169-179.

Bach, T., Fleischer, J., \& Hustedt, T. (2010). Organization und Steuerung Zentralstaatlicher Behörden. Agenturen im Westeuropäischen Vergleich [Organization and Control of the Central Government Agencies in Western European Comparison]. Berlin, Germany: Edition Sigma.

Balcetis, E., \& Cole, S. (2013). On misers, managers, and monsters: The social cognition of visual perception. In D. E. Carlston (Ed.), The Oxford handbook of social cognition (pp. 329-351). Oxford: Oxford University Press.

Bargh, J. A. (1984). Automatic and conscious processing of social information. In R. S. Wyer, R. S. \& T. K. Srull (Eds.), Handbook of social cognition (pp. 1-43). Hillsdale, NJ: Erlbaum.

Bertelli, A. M., \& Grose, C. R. (2009). Secretaries of pork: A new theory of distributive policy. Journal of Politics, 71(3), 926-945.

Bertelli, A. M., \& Grose, C. R. (2011). The lengthened shadow of another institution? Ideal point estimates for the executive branch and congress. American Journal of Political Science, 55, 767-781.

Busuioc, M., \& Groenleer, M. (2012). Wielders of supranational power? The administrative behaviour of the heads of European Union agencies. In M. Busuioc, M. Groenleer, \& J. Trondal (Eds.), The agency phenomenon in the European Union: Emergence, institutionalisation and everyday decision-making (pp. 128-151). Manchester, UK: Manchester University Press.

Busuioc, M., \& Lodge, M. (2015). The reputational basis of public accountability. Governance, 29(2), 247-263. doi:10.1111/gove.12161

Calvert, R. L., McCubbins, M. D., \& Weingast, B. R. (1989). A theory of political control and agency dis- cretion. American Journal of Political Science, 33(3), 588-611.

Carpenter, D. P. (2001). The forging of bureaucratic autonomy: Reputation, networks, and policy innovation in executive agencies, 1862-1928. Princeton, NJ: Princeton University Press.

Carpenter, D. P. (2002). Groups, the media, agency waiting costs, and FDA drug approval. American Journal of Political Science, 46, 490-505.

Carpenter, D. P. (2010a). Reputation and power: Organizational image and pharmaceutical regulation at the FDA. Princeton: Princeton University Press.

Carpenter, D. P. (2010b). Institutional strangulation: Bureaucratic politics and financial reform in the Obama administration. Perspectives on Politics, 8, 825-846.

Carpenter, D. P., \& Krause, G. A. (2012). Reputation and public administration. Public Administration Review, 72(1), 26-32.

Carpenter, D. P., \& Krause, G. A. (2015). Transactional authority and bureaucratic politics. Journal of Public Administration Research and Theory, 25(1), 5-25.

Chen, C. C., \& Meindl, J. R. (1991). The construction of leadership images in the popular press: The case of Donald Burr and people express. Administrative Science Quarterly, 36(4), 521-551.

Clinton, J. D., Bertelli, A., Grose, C., Lewis, D. E., \& Nixon, D. C. (2012). Separated powers in the United States: The ideologies of agencies, presidents, and Congress. American Journal of Political Science, 56, 341-354.

Clinton, J. D., \& Lewis, D. E. (2008). Expert opinion, agency characteristics, and agency preferences. Political Analysis, 16(1), 3-20.

Clore, L. G., \& Palmer, J. (2009). Affective guidance of intelligent agents: How emotion controls cognition. Cognitive Systems Research, 10(1), 21-30.

Dewatripont, M., Jewitt, I., \& Tirole, J. (1999). The economics of career concerns, part II: Applications to missions and accountability of government agencies. Review of Economic Studies, 66, 199-217.

Dowling, G. R., \& Gardberg, N. A. (2012). Keeping score: The challenges of measuring corporate reputation. In M. Barnet \& T. Pollock (Eds.), The Oxford handbook of corporate reputation (pp. 34-68). Oxford: Oxford University Press.

Duffy, S., \& Kitayama, S. (2010). Cultural modes of seeing through cultural modes of being: Cultural influences on visual attention. In E. Balcetis \& G. D. Lassiter (Eds.), Social psychology of visual perception (pp. 5175). New York: Psychology Press.

Finucane, M. L. (2013). The role of feelings in perceived risk. In S. Roeser, R. Hillerbrand, P. Sandin, \& M. Peterson (Eds.), Essentials of risk theory (pp. 57-74). Dordrecht, The Netherlands: Springer.

Finucane, M. L., Alhakami, A., Slovic, P., \& Johnson, S. M. (2000). The affect heuristic in judgment of risks and benefits. Journal of Behavioral Decision Making, 13, 1-17. 
Finucane, M. L., Peters, E., \& Slovic, P. (2003). Judgment and decision making: The dance of affect and reason. In S. Schneider \& J. Shanteau (Eds.), Emerging perspectives on judgment and decision research (pp. 327-364). Cambridge: Cambridge University Press.

Fombrun, C. (2012). The building blocks of corporate reputation: Definitions, antecedents, consequences. In M. Barnet \& T. Pollock (Eds.), The Oxford handbook of corporate reputation (pp. 94-113). Oxford: Oxford University Press.

Forgas, J. P. (1992). Affect in social judgments and decisions: A multiprocess model. In M. P. Zanna (Ed.), Advances in experimental social psychology. (Vol. 25, pp. 227-275). San Diego, CA: Academic Press.

Gilad, S. (2012). Regulatory attention and reputation. In M. Lodge \& K. Wegrich (Eds.), Executive politics in times of crisis (pp. 157-178). Basingstoke, England: Palgrave Macmillan.

Gilad, S., Maor, M., \& Ben-Nun Bloom, P. (2015). Organizational reputation, the content of public allegations and regulatory communication. Journal of Public Administration Research and Theory, 25(2), 451-478.

Goffman, E. (1959). Presentation of self in everyday life. London: Penguin.

Graffin, S. D., Pfarrer, M. D., \& Hill, M. W. (2012). Untangling executive reputation and corporate reputation: Who made who? In M. L. Barnett \& T. G. Pollock (Eds.), The Oxford handbook of corporate reputation (pp. 221-239). Oxford: Oxford University Press.

Greenwald, A. G. (1980). The totalitarian ego: Fabrication and revision of personal history. American Psychologist, 35(7), 603-618.

Greenwood, R., Li, S. X., Parkish, R., \& Deephouse, D. L. (2005). Reputation, diversification, and organizational explanations of performance in professional service firms. Organization Science, 16(6), 661-673.

Groenleer, M. L. P. (2014). Agency autonomy actually: Managerial strategies, legitimacy, and the early development of the European Union's agencies for drug and food safety regulation. International Public Management Journal, 17(2), 255-292.

Hammond, T. H., \& Knott, J. H. (1996). Who controls the bureaucracy? Presidential power, congressional dominance, legal constraints, and bureaucratic autonomy in a model of multi-institutional policymaking. Journal of Law, Economics, and Organization, 12(1), 119-166.

Heimann, C. F. L. (1997). Acceptable risks: Politics, policy and risky technologies. Ann Arbor: University of Michigan Press.

Hood, C. (2011). The blame game: Spin, bureaucracy, and self-preservation in government. Princeton: Princeton University Press.

Huber, G. A. (2007). The craft of bureaucratic neutrality: Interest and influence in governmental regulation of occupational safety. New York, NY: Cambridge University Press.
Jacobsen, R. J., Snyder, W., \& Saultz, A. (2014). Understanding satisfaction with schools: The role of expectations. Journal of Public Administration Research and Theory, 25(3), 831-848.

Jensen, M., Kim, H., \& Kim, B. K. (2012). Meeting expectations: A role-theoretic perspective on reputation. In M. Barnet \& T. Pollock (Eds.), The Oxford handbook of corporate reputation (pp. 140-159). Oxford: Oxford University Press.

Jensen, M., \& Roy, A. (2008). Staging exchange partner choices: When do status and reputation matter? Academy of Management Journal, 51(3), 495-516.

Kaufman, H. (1981). The administrative behavior of federal bureau chiefs. Washington, DC: Brookings Institution Press.

Kiewiet, D. R., \& McCubbins, M. D. (1991). The logic of delegation. Chicago: The University of Chicago Press.

Krause, G. A., \& O'Connell, A. J. (2015). Can bureaucratic leadership mitigate common agency problems? $\mathrm{Pa}$ per presented at the American Politics Workshop, University of Chicago.

Kreps, D. M. (1990). Corporate culture and economic theory. In J. E. Alt \& K. A. Shepsle (Eds.), Perspectives on positive political Economy (90-143). New York: Cambridge University Press.

Lavertu, S. (2015). We all need help: "Big data" and the mismeasure of public administration. Public Administration Review. doi:10.1111/puar.12436

LeDoux, J. (1996). The emotional brain. New York: Simon \& Schuster

Lewis, D. E. (2002). The politics of agency termination: Confronting the myth of agency immortality. Journal of Politics, 64(1), 89-107.

Lodge, M., \& Taber, C. S. (2013). The rationalizing voter. Cambridge, NY: Cambridge University Press.

Maor, M. (2007). A scientific standard and an agency's legal independence: Which of these reputationprotection mechanisms is less susceptible to political moves. Public Administration, 85(4), 961-978.

Maor, M. (2010). Organizational reputation and jurisdictional claims: The case of the U.S. food and drug administration. Governance, 23(1), 133-159.

Maor, M. (2011). Organizational reputations and the observability of public warnings in 10 pharmaceutical markets. Governance, 24(3), 557-582.

Maor, M. (2015). Theorizing bureaucratic reputation. In A. Wæraas \& M. Maor (Eds.), Organizational reputation in the public sector (pp. 17-36). London: Routledge.

Maor, M. (forthcoming). Strategic silence. In C. E. Carroll (Ed.), SAGE encyclopedia of corporate reputation. London: Sage.

Maor, M., Gilad, S., \& Ben-Nun Bloom, P. (2013). Organizational reputation, regulatory talk and strategic silence. Journal of Public Administration Research and Theory, 23, 581-608.

Maor, M., \& Gross, J. (2015) Emotion regulation by emo- 
tional entrepreneurs: Implications for political science and international relations. Paper presented at the 73rd Annual Conference of the Midwest Political Science Association, Chicago.

Maor, M., \& Sulitzeanu-Kenan, R. (2013). The effect of salient reputational threats on the pace of FDA enforcement. Governance, 26(1), 31-61.

Maor, M., \& Sulitzeanu-Kenan, R. (2016). Responsive change: Agency output response to reputational threats. Journal of Public Administration Research and Theory, 26(1), 31-44.

March, J. G., \& Simon, H. (1992). Organizations (2nd ed.). Cambridge, MA: Blackwell Publishers.

Milbourn, T. T. (2003). CEO reputation and stock-based compensation. Journal of Financial Economics, 68, 233-262.

Moe, T. M. (1984). The new economics of organization. American Journal of Political Science, 28(4), 739-77.

Najmi, S. (2013). Thought suppression. In D. E. Carlston (Ed.), The Oxford handbook of social cognition (pp. 417-432). Oxford: Oxford University Press.

Nixon, D. C. (2004). Separation of powers and appointee ideology. Journal of Law, Economics, and Organization, 20, 438-457.

Peters, E. (2011). Affect and emotion. In B. Fischhoff, N. T. Brewer, \& J. S. Downs (Eds.), Communicating risks and benefits: An evidence-based user's guide (pp. 8999). Washington, DC: US Department of Health and Human Services.

Petkova, A. (2012). From the ground up: Building young firms' reputations. In M. Barnett \& T. Pollock (Eds.), Oxford handbook of corporate reputation (pp. 383401). Oxford: Oxford University Press.

Power, M., Scheytt, T., Soin, K., \& Sahlin, K. (2009). Reputational risk as a logic of organizing in late modernity. Organization Studies, 30, 301-324.

Quirk, P. (1980). The food and drug administration. In J. Q. Wilson (Ed.), The politics of regulation (pp. 226232). New York: Basic Books.

Rick, S., \& Loewenstein, G. (2010). The role of emotion in economic behavior. In M. Lewis, J. M. HavilandJones, \& L. Feldman-Barrett (Eds.), Handbook of emotions (3rd ed., pp. 138-158). New York: Guilford Press

Riker, W. H. (1986). The art of political manipulation. New Haven: Yale University Press.

Rourke, F. E. (1984). Bureaucracy, politics, and public policy. Boston, MA: Little, Brown.

Seidman, H., \& Gilmour, R. (1998). Politics, position, and power (5th ed.). New York: Oxford University Press.

Selznick, P. (1957). Leadership in administration: A sociological interpretation. Berkeley: University of California Press.

Wæraas, A., \& Byrkjeflot, H. (2012). Public sector organizations and reputation management: Five problems. International Public Management Journal, 15(2), 186-206.

Wæraas, A., \& Maor, M. (2015). Understanding organizational reputation in a public sector context. In A. Wæraas \& M. Maor (Eds.), Organizational reputation in the public sector (pp. 1-14). London: Routledge.

Washington, M., \& Zajac, E. J. (2005). By invitation only: The institutional evolution of status and privilege. Academy of Management Journal, 48(2), 281-296.

Weber, M. (1946). Bureaucracy. In H. H. Gerth \& C. W. Mills (Eds.), Essays in sociology (pp. 196-233). New York: Oxford University Press.

Whitford, A. B. (2002). Bureaucratic discretion, agency structure, and democratic responsiveness: The case of the United States attorneys. Journal of Public Administration Research and Theory, 12(1), 3-27.

Wilson, J. Q. (1989). Bureaucracy: What government agencies do and why they do it. New York: Basic Books.

Zajonc, R. B. (1980). Feeling and thinking: Preferences need no inference. American Psychologist, 35(2), 151-175.

Zajonc, R. B. (1984). The interaction of affect and cognition. In K. R. Scherer \& P. Ekman (Eds.), Approaches to emotion (pp. 239-246). Hillsdale, NJ: Erlbaum.

Zuckerman, E. W. (1999). The categorical imperative: Securities analysts and the illegitimacy discount. American Journal of Sociology, 104(5), 1398-1438.

\section{About the Author}

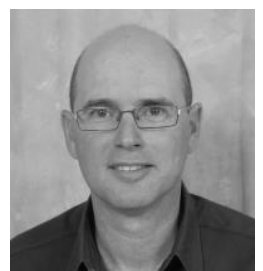

Moshe Maor is Professor of Political Science and holder of the Wolfson Family Chair of Public Administration at the Hebrew University of Jerusalem. His areas of expertise are bureaucratic politics and public policy. He is the author of numerous articles in J-PART, Policy Sciences, Governance, Journal of Public Policy, Public Administration, European Journal of Political Research, Journal of European Public Policy, West European Politics, Journal of Theoretical Politics, Public Administration Review, Administration \& Society, Democratization, Disaster, and Israel Affairs. 